\title{
Quantitative proteomics reveals molecular mechanism of gamabufotalin and its potential inhibition on Hsp90 in lung cancer
}

\author{
Liyuan Zhang ${ }^{1, *}$, Zhenlong Yu ${ }^{1,2, *}$, Yan Wang ${ }^{1,2}$, Xiaobo Wang ${ }^{2}$, Lianru Zhang ${ }^{3}$, Chao \\ Wang $^{1}$, Qingxi Yue ${ }^{1,4}$, Xun Wang ${ }^{5}$, Sa Deng ${ }^{1}$, Xiaokui Huo ${ }^{1}$, Xiangge Tian ${ }^{1}$, Shanshan \\ Huang $^{1}$, Baojing Zhang ${ }^{1}$, Xiaochi Ma ${ }^{1}$ \\ ${ }^{1}$ Dalian Medical University, Dalian, China \\ ${ }^{2}$ Department of Pharmacy and Traditional Chinese Medicine, Chinese People's Liberation Army 210 Hospital, Dalian, China \\ ${ }^{3}$ State Key Lab of Cellular Stress Biology, School of Life Sciences, Xiamen University, Xiamen, China \\ ${ }^{4}$ Institute of Oncology, Shanghai 9th People's Hospital, Shanghai JiaoTong University School of Medicine, Shanghai, China \\ ${ }^{5}$ Department of Nuerosurgery, the Third People's Hospital of Dalian, Non-Directly Affiliated Hospital of Dalian Medical \\ University, Dalian, China \\ *These authors contributed equally to this work
}

Correspondence to: Xiaobo Wang, email: wxbbenson0653@sina.com

Qingxi Yue, email: qxyue@sibs.ac.cn

Xiaochi Ma, email: maxc1978@163.com

Keywords: gamabufotalin, heat shock protein 90 (Hsp90), quantitative proteomics, gene ontology (GO), NSCLC

Received: March 10, $2016 \quad$ Accepted: May 05, $2016 \quad$ Published: July 02, 2016

\section{ABSTRACT}

Gamabufotalin (CS-6) is a major bufadienolide of Chansu, which shows desirable metabolic stability and less adverse effect in cancer therapy. CS- 6 treatment inhibited the proliferation of NSCLC in a nanomolar range. And CS-6 could induce G2/M cell cycle arrest and apoptosis in A549 cells. However, its molecular mechanism in antitumor activity remains poorly understood. We employed a quantitative proteomics approach to identify the potential cellular targets of CS-6, and found 38 possible target-related proteins. Among them, 31 proteins were closely related in the protein-protein interaction network. One of the regulatory nodes in key pathways was occupied by Hsp90. Molecular docking revealed that CS-6 interacted with the ATP-binding sites of Hsp90. In addition, CS-6 inhibited the chaperone function of Hsp90 and reduced expression of Hsp90-dependent client proteins. Moreover, CS-6 markedly downregulated the protein level of Hsp90 in tumor tissues of the xenograft mice. Taken together, our results suggest that CS-6 might be a novel inhibitor of Hsp90, and the possible network associated with CS-6 target-related proteins was constructed, which provided experimental evidence for the preclinical value of using CS- 6 as an effective antitumor agent in treatment of NSCLC.

\section{INTRODUCTION}

Lung cancer remains the leading cancer killer around the world [1], especially in China [2], over $85 \%$ of lung cancers are diagnosed as non-small cell lung cancer (NSCLC), with 1-year survival rate below 15\% [3]. Advanced NSCLC is often treated with radiation therapy or chemotherapy, which could lead many side effects and even increase a person's risk in developing second cancers later in life. More research is urgently needed to explore new therapy strategies that not only improve the survival rate, but also eliminate suffering of patients with lung cancer.

Most recently, natural products isolated from traditional Chinese medicines have drawn more attentions, due to their great potential in antitumor activities $[4,5]$ with low toxicity and few side effects. Bufadienolides are the major bioactive constituents found in Toad venom, which is from the postauricular glands and skin secretions of Bufo bufo gargarizans Cantor or Bufo melanostictus Schneider [6]. Several in vitro and in vivo studies have demonstrated anti-cancer effects of bufadienolides in 
various cancers $[7,8]$. Gamabufotalin (CS-6), a major derivative of bufadienolides, has shown significant antitumor activity, with stable metabolic properties and less adverse effects in previous work [9-11], compared with other bufadienolides. However, as a bioactive molecular, the key signal pathways underlying the anti-cancer mechanism, and the therapeutic targets of CS-6 had not yet been well characterized.

Quantitative proteomics techniques have recently emerged as a robust tool to uncover the differential proteins expression associated with mechanism and therapeutic targets of natural products. The most accurate mass spectrometry based quantitative approach is typically performed by stable isotope labeling. Stable isotope dimethyl labeling [12-14] provides a very straightforward, fast and inexpensive means for quantitative proteomics, compared with other quantitative strategies.

In the present study, the molecular mechanism of the anti-cancer effects of CS-6 was deciphered by interrogating the proteomics changes incurred in A549 cells after exposure to CS-6. For this purpose, stable isotope-based dimethyl labeling together with nanoscale liquid chromatography-mass spectrometry were employed. The quantitative proteomics combined with bioinformatics has been proven to be a powerful tool to reveal the complex molecular events in biological systems, which enable us to quantitate the changes in proteins from a broad array of biochemical and signaling pathways. Thus, a comprehensive bioinformatics analysis was conducted to figure the biological pathways in response to CS-6 activation. The results indicated that several key proteins in cell signaling and tumor regeneration, including heat shock protein 90 (Hsp90), might be involved in the anti-cancer effect of CS-6 in A549 cells. The predicted binding between CS-6 and Hsp90 was then verified by molecular docking. Our results show that CS-6 might be a potential inhibitor of Hsp90, which shed more light on the mechanism of anti-cancer effects of CS-6.

\section{RESULTS}

\section{Effects of CS-6 on cell viability and morphological changes of A549 cells}

As shown in Figure 1A, the survival rate of A549 cells was reduced in a dose- and time-dependent manner after treatment with increasing concentrations of CS-6 $(0,5,10,50,100$ and $500 \mathrm{nM})$ for 24,36 and $48 \mathrm{~h}$. However, no obvious cytotoxicity was observed in human normal lung cell line (HLF cells) at the same dose (Figure 1B). The $\mathrm{IC}_{50}$ value of CS-6 was $48.4 \pm$ $2.5 \mathrm{nM}$ for $48 \mathrm{~h}$ treatment. The morphological changes of A549 cells caused by $36 \mathrm{~h}$ exposure to the various concentrations of CS-6 $(0,10$ and $50 \mathrm{nM})$ are shown in Figure 1C. As the concentration of CS-6 increased, shrunk cells and plasma membrane blebs were exhibited.
The AO/EB double staining showed that viable cells with intact DNA and nucleus show a round and green nuclei, while late apoptotic and necrotic cells with fragmented DNA display an orange to red nuclei. As shown in Figure 1D, CS-6 exposure induced late apoptotic and necrotic cells, and increasing concentration of CS-6, the number of viable cells decreased tremendously. In addition, the chromatin of nuclei condensed and nuclear apoptotic bodies were formed when cancer cells were treated with CS-6. Furthermore, as shown in Figure 1E, after treatment with CS-6 for $36 \mathrm{~h}$, the representative DNA histograms of A549 cells showed that the percentages of G0/G1 phase were decreased from $55.67 \%$ to $36.46 \%$, whereas $\mathrm{G} 2 / \mathrm{M}$ phase were increased from $16.89 \%$ to $34.88 \%$, S phase were not affected by $50 \mathrm{nM}$ CS-6, compared with the control group. These results fully indicated that CS-6 at 10 and $50 \mathrm{nM}$ could both induce G2/M phase arrest of A549 cells. Together, these results suggested that CS-6 could trigger the programmed cell death of A549 cells, while it have no obvious impact on the normal cells.

\section{Effect of CS-6 on proteome profile of A549 cells}

Accurate and high throughput quantification of differentially expressed proteins is great essential to further decipher the mechanism of cell toxicity induced by CS-6; stable isotope dimethyl labeling based quantitative proteomics strategy with the advantages of low cost, rapid and high derivatization efficiency was employed. As a result, 493 proteins were quantified in all thrice quantification when controlling the RSD of the ratios for the quantified proteins to less than $50 \%$, of which, 38 proteins were quantified with at least a 2 -fold change with statistical significance $(p$-value $<0.05)$ (Table 1).

More detailed information about these differentially expressed proteins is presented in Table 1. Among these 38 differential proteins, 5 proteins were up-regulated (ratio $>2$ ) and 33 proteins were down-regulated (ratio $<0.5$ ) by the treatment of CS- 6 . The fold change and direction of CS-6-modulated proteins are represented in Figure 2.

\section{Gene ontology analysis of differentially expressed proteins}

To better characterize the 38 differentially expressed proteins, the Gene Ontology (GO), including "Biological Processes", "Molecular Function", and "Cellular Component" was performed with Blast2GO using standard parameters. The biological processes of the significantly differentially expressed proteins were most enriched in regulation of cellular, metabolic, single-organism and biological process (Figure 3A). The categorical analysis of molecular function revealed that the majority of these proteins were classified into binding, catalytic activity, and structural molecule activity, and enzyme regulator activity (Figure 3B). Most of identified annotated proteins were 
Table 1: Details about differentially expressed proteins upon CS-6 treatment, showing $>2$ fold up- or down-regulation with statistical significance

\begin{tabular}{|c|c|c|c|c|c|c|c|c|c|}
\hline No. & $\begin{array}{c}\text { IPI } \\
\text { Accession }\end{array}$ & $\begin{array}{c}\text { Gi } \\
\text { Accession }\end{array}$ & Protein Name & $\begin{array}{c}\text { Pepties } \\
\text { matched }\end{array}$ & $\begin{array}{l}\text { Unique } \\
\text { peptides }\end{array}$ & $\begin{array}{c}\text { Sequence } \\
\text { Coverage } \\
(\%)\end{array}$ & MW & $\begin{array}{l}\text { Ratio } \\
\text { of } D \\
\text { to } H \\
\end{array}$ & $p$-value \\
\hline 1 & IPI00014230 & C1QBP & $\begin{array}{c}\text { Complement } \\
\text { component } 1 \mathrm{Q} \\
\text { subcomponent-binding } \\
\text { protein }\end{array}$ & 6 & 6 & 32.6 & 31.362 & 0.35 & 0.001 \\
\hline 2 & IPI00414676 & HSP90AB1 & $\begin{array}{c}\text { Heat shock protein } \\
\text { HSP 90-beta }\end{array}$ & 30 & 9 & 43.9 & 83.263 & 0.41 & 0.005 \\
\hline 3 & IPI00024993 & ECHS1 & $\begin{array}{c}\text { Enoyl-CoA hydratase } \\
\text { mitochondrial }\end{array}$ & 2 & 2 & 12.1 & 31.387 & 0.41 & 0.016 \\
\hline 4 & IPI00023860 & NAP1L1 & $\begin{array}{c}\text { Nucleosome assembly } \\
\text { protein 1-like } 1\end{array}$ & 6 & 5 & 25.1 & 45.374 & 0.32 & 0.003 \\
\hline 5 & IPI00026271 & RPS14 & $\begin{array}{c}\text { 40S ribosomal protein } \\
\text { S14 }\end{array}$ & 1 & 2 & 15.1 & 16.273 & 0.31 & 0.017 \\
\hline 6 & IPI00293276 & MIF & $\begin{array}{c}\text { Macrophage migration } \\
\text { inhibitory factor }\end{array}$ & 1 & 1 & 7.8 & 12.476 & 0.28 & $<0.001$ \\
\hline 7 & IPI00026546 & PAFAH1B2 & $\begin{array}{c}\text { Platelet-activating } \\
\text { factor acetylhydrolase } \\
\text { IB subunit beta }\end{array}$ & 1 & 1 & 3.9 & 25.569 & 0.27 & 0.02 \\
\hline 8 & IPI00306332 & RPL24 & $\begin{array}{c}\text { 60S ribosomal protein } \\
\text { L24 }\end{array}$ & 2 & 2 & 13.4 & 17.779 & 0.33 & 0.035 \\
\hline 9 & IPI00007797 & FABP5 & $\begin{array}{l}\text { Fatty acid-binding } \\
\text { protein, epidermal }\end{array}$ & 2 & 2 & 22.2 & 15.164 & 0.30 & 0.008 \\
\hline 10 & IPI00789101 & PTGES3 & $\begin{array}{c}\text { Prostaglandin E } \\
\text { Synthase } 3\end{array}$ & 4 & 4 & 30.3 & 19.448 & 0.32 & 0.005 \\
\hline 11 & IPI00219153 & RPL22 & $\begin{array}{c}\text { 60S ribosomal protein } \\
\text { L22 }\end{array}$ & 3 & 3 & 39.1 & 14.787 & 0.31 & 0.031 \\
\hline 12 & IPI00646304 & PPIB & $\begin{array}{l}\text { Peptidyl-prolyl cis- } \\
\text { trans isomerase B }\end{array}$ & 9 & 8 & 38 & 23.742 & 0.30 & 0.005 \\
\hline 13 & IPI00013068 & EIF3E & $\begin{array}{c}\text { Eukaryotic translation } \\
\text { initiation factor } 3 \\
\text { subunit E }\end{array}$ & 3 & 3 & 10.6 & 52.22 & 0.41 & 0.034 \\
\hline 14 & IPI00980853 & RHOC & $\begin{array}{c}\text { Rho-related GTP- } \\
\text { binding protein RhoC }\end{array}$ & 2 & 1 & 18.8 & 25.485 & 0.45 & 0.048 \\
\hline 15 & IPI00789041 & $\mathrm{PNN}$ & Pinin & 1 & 1 & 1.8 & 81.613 & 50.00 & $<0.001$ \\
\hline 16 & IPI00006167 & PPM1G & $\begin{array}{c}\text { Protein phosphatase } \\
1 \mathrm{G}\end{array}$ & 1 & 1 & 5.3 & 59.271 & 0.17 & $<0.001$ \\
\hline 17 & IPI00761160 & CAST & Calpastatin & 1 & 1 & 3.7 & 84.942 & 0.34 & 0.017 \\
\hline 18 & IPI00013895 & S100A11 & $\begin{array}{c}\text { S100 calcium binding } \\
\text { protein A11 }\end{array}$ & 4 & 4 & 42.9 & 11.74 & 0.34 & 0.039 \\
\hline 19 & IPI00003217 & PSMB7 & $\begin{array}{c}\text { Proteasome subunit } \\
\text { beta type- } 7\end{array}$ & 4 & 4 & 23.8 & 29.965 & 0.41 & 0.044 \\
\hline 20 & IPI00219038 & H3F3A & $\begin{array}{c}\text { H3 Histone, Family } \\
\text { 3A (H3F3A) }\end{array}$ & 4 & 4 & 25 & 15.328 & 2.70 & $<0.001$ \\
\hline 21 & IPI00015361 & PFDN5 & Prefoldin subunit 5 & 1 & 1 & 11.7 & 17.328 & 0.29 & $<0.001$ \\
\hline 22 & IPI00013004 & PDXK & Pyridoxal kinase & 2 & 2 & 11.9 & 35.102 & 0.43 & 0.002 \\
\hline
\end{tabular}




\begin{tabular}{|c|c|c|c|c|c|c|c|c|c|}
\hline 23 & IPI00719622 & RPS28 & $\begin{array}{l}\text { 40S ribosomal protein } \\
\text { S28 }\end{array}$ & 2 & 2 & 30.4 & 7.8409 & 0.37 & 0.004 \\
\hline 24 & IPI00219037 & H2AFX & Histone H2AX & 4 & 1 & 32.2 & 15.144 & 0.36 & 0.002 \\
\hline 25 & IPI00015077 & EIF1 & $\begin{array}{l}\text { Eukaryotic translation } \\
\text { initiation factor } 1\end{array}$ & 3 & 3 & 45.1 & 12.732 & 0.35 & 0.009 \\
\hline 26 & IPI00165393 & ANP32E & $\begin{array}{l}\text { Acidic leucine- } \\
\text { rich nuclear } \\
\text { phosphoprotein } 32 \\
\text { family member E }\end{array}$ & 3 & 3 & 17.9 & 30.692 & 0.45 & 0.01 \\
\hline 27 & IPI00298547 & PARK7 & $\begin{array}{l}\text { Parkinson disease } \\
\text { protein } 7\end{array}$ & 3 & 3 & 31.7 & 19.891 & 0.35 & 0.015 \\
\hline 28 & IPI00031420 & UGDH & $\begin{array}{c}\text { UDP-glucose } \\
\text { 6-dehydrogenase }\end{array}$ & 17 & 17 & 50.4 & 55.023 & 0.39 & 0.016 \\
\hline 29 & IPI00215914 & ARF1 & $\begin{array}{c}\text { ADP-ribosylation } \\
\text { factor } 1\end{array}$ & 3 & 3 & 19.9 & 20.697 & 0.46 & 0.032 \\
\hline 30 & IPI00302850 & SNRPD1 & $\begin{array}{c}\text { Small nuclear } \\
\text { ribonucleoprotein Sm } \\
\text { D1 }\end{array}$ & 1 & 1 & 16.8 & 13.281 & 0.37 & $<0.001$ \\
\hline 31 & IPI00021258 & ARFIP1 & $\begin{array}{l}\text { ADP-ribosylation } \\
\text { factor-interacting } \\
\text { protein } 1\end{array}$ & 1 & 1 & 2.7 & 41.738 & 8.33 & $<0.001$ \\
\hline 32 & IPI00031691 & RPL9 & $\begin{array}{l}\text { 60S ribosomal protein } \\
\text { L9 }\end{array}$ & 4 & 4 & 36.5 & 21.863 & 0.41 & 0.026 \\
\hline 33 & IPI00176903 & PTRF & $\begin{array}{c}\text { Polymerase I and } \\
\text { transcript release } \\
\text { factor }\end{array}$ & 1 & 1 & 4.6 & 43.476 & 0.38 & 0.004 \\
\hline 34 & IPI00376005 & EIF5A & $\begin{array}{l}\text { Eukaryotic translation } \\
\text { initiation factor } 5 \mathrm{~A}-1\end{array}$ & 10 & 10 & 57.6 & 20.17 & 0.48 & 0.026 \\
\hline 35 & IPI00473079 & UGT1A3 & $\begin{array}{l}\text { UDP-glucuronosy } \\
\text { ltransferase } 1 \mathrm{~A} 3\end{array}$ & 1 & 1 & 3.9 & 60.338 & 0.24 & 0.025 \\
\hline 36 & IPI00783982 & COPG & $\begin{array}{l}\text { Coatomer subunit } \\
\text { gamma-1 }\end{array}$ & 2 & 2 & 2.9 & 97.717 & 0.40 & 0.039 \\
\hline 37 & IPI00791020 & GALNT13 & $\begin{array}{c}\text { Polypeptide } \\
\text { N-acetylgalactosam } \\
\text { inyltransferase } 13\end{array}$ & 1 & 1 & 1.1 & 64.624 & 27.80 & $<0.001$ \\
\hline 38 & IPI00005981 & TAGLN3 & Transgelin-3 & 1 & 1 & 6.3 & 25.01 & 7.76 & 0.001 \\
\hline
\end{tabular}

located in the organelle, macromolecular complex (14\%), membrane and membrane-enclosed lumen, respectively (Figure 3C). Taken together, the data from gene ontology reveal that CS-6 affects multiple critical cellular processes relevant to cell growth and proliferation.

Additionally, the protein-protein networks of CS-6 modulated proteins were analyzed with Cytoscape 3.1 network analysis. The networks formed by the identified proteins provided insights into the potential mechanisms and biological processes that regulated by CS-6. In this study, 31 proteins could link together into one network through direct interaction or only one intermediate partner (Figure 3D), suggesting the inherent correlation among all of them. These interacting proteins include the ribosome proteins, RNA transport proteins, apoptotic proteins and metabolic process proteins. It is interesting to note that the transcription factor NF- $\mathrm{KB}$, was also observed in the network, which was reported as the potential target of CS-6 in our previous work [9].

\section{Confirmation of differentially expressed proteins by Western blotting}

Data from the mass spectrometric results and the protein-protein networks profiling shown by Cytoscape analysis have revealed the proteins differentially up and down regulated by CS-6. Many differentially expressed proteins are identified as multiple central 
nodes, such as Hsp90AB1 (Heat shock protein Hsp 90beta), ECSH1 (Enoyl-CoA hydratase, mitochondrial), NAP1L1 (Nucleosome assembly protein 1-like 1), MIF (Macrophage migration inhibitory factor), PTGES3 (Prostaglandin E Synthase 3), PNN (Pinin) and et al. The expression of some identified target proteins were chosen to be validated in control and CS-6 treated A549 cells (for 36h) through western blotting assay. Consistent with the proteomics results, Hsp90, NAP1L1, ECSH1 and PTGES3 were found to be down-regulated, whereas ARFIP1 and PNN were found to be up-regulated in CS-6 treated A549 cells (Figure 4).

\section{Western-blotting analysis of senescence and growth associated Hsp90 client proteins after CS-6 treatment}

From the protein-protein networks, we found that Hsp90AB1 was the key central node, as it had the biggest interaction with other proteins in the network. In addition, our previous work demonstrated that CS-6 targeted IKK $\beta$ / $\mathrm{NF}-\kappa \mathrm{B}$ to prohibit lung cancer growth; however, IKK was one member of Hsp90 client protein [15], which also suggesting that Hsp90 was an important protein. We hypothesized that Hsp90AB1 was the most important protein molecules that was affected by CS-6 treatment in A549cells. Hsp90 is a molecular chaperone that plays an indispensable role in normal cellular homeostasis by regulating the folding, stability, and function of its target substrates, termed "client" proteins $[16,17]$, many of which have effects in regulating signal transduction pathways. We next detected the expression of Hsp90 client proteins after CS-6 treatment. The expression of senescence, proliferation and cell cycle associated Hsp90 client oncoproteins, like hTERT, HIF-1 $\alpha$, VEGF, CDK4, HER2 and Akt were analyzed in CS-6-treated A549 cells. At the concentration of $50 \mathrm{nM}$, the protein expression levels of hTERT, HIF-1 $\alpha$, VEGF, CDK4, HER2 and p-Akt were significantly reduced (Figure $5 \mathrm{~A}$ ), while Akt protein level didn't change obviously. Besides, the expression of some commonly overexpressed oncoproteins in NSCLC, known as proteins in Hsp90 client signaling pathway were also detected. As shown in Figure 5B, the expression of Cyclin D1, p110 $\alpha$ and p-p85 were significantly downregulated at the concentration of $50 \mathrm{nM}$.

To determine whether CS-6 also inhibited Hsp90 expression in other NSCLC cells, we further treated H1299, H322 and H460 cells with CS-6 at different doses, and found that CS-6 also considerably suppressed Hsp90 protein expression in H1299, H322 and H460 cells (Figure 5C).

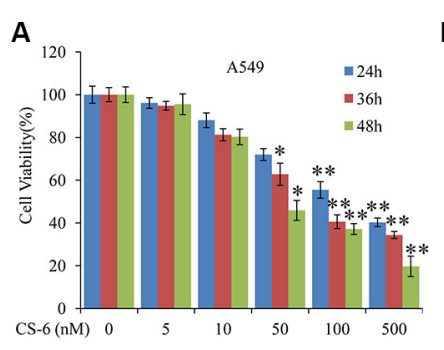

D
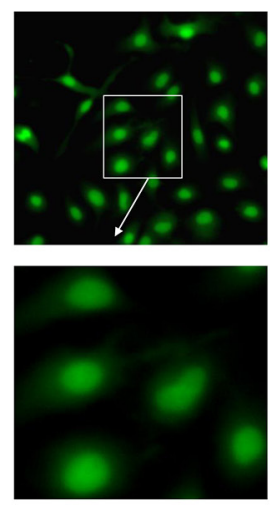

CS- $6(0 \mathrm{nM})$
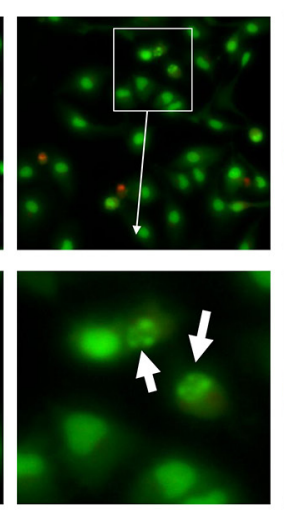

CS- $6(10 \mathrm{nM})$
B
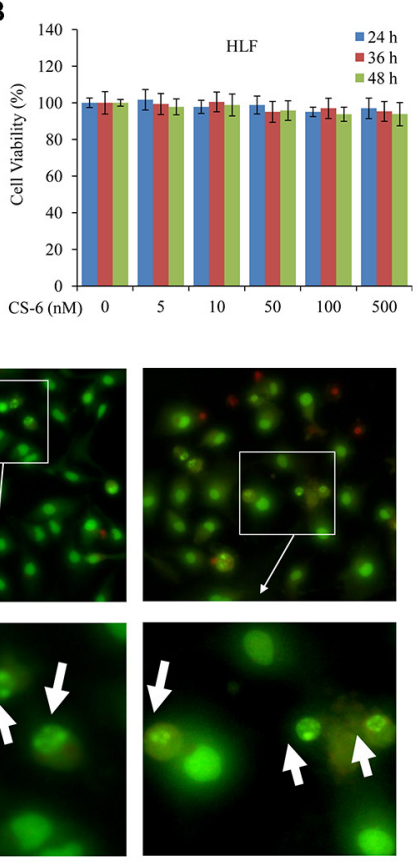

CS-6 (50 nM)
C
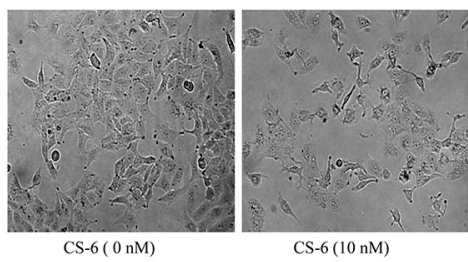

CS-6 (10 nM)

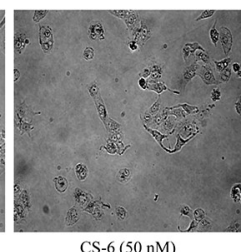

CS-6 (50 nM)

E
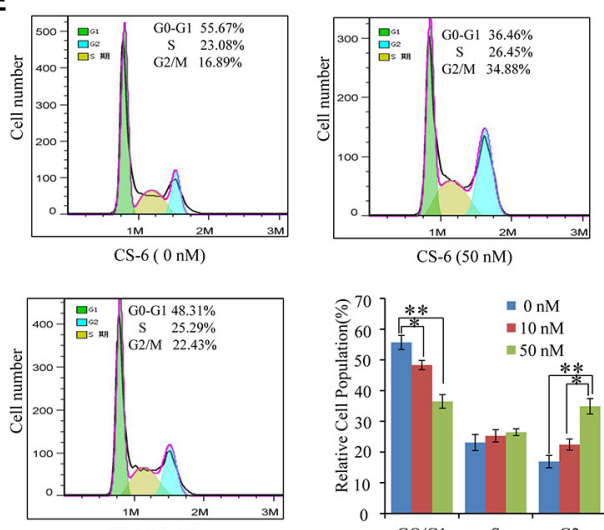

CS- $6(10 \mathrm{nM})$

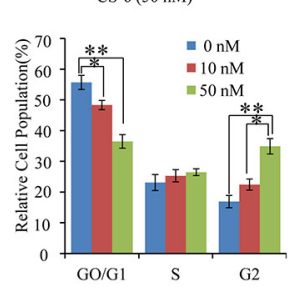

Figure 1: CS-6 inhibited cell viability and changed morphology. (A) A549 and (B) HLF cells were treated with 5, 10, 50, 100 and $500 \mathrm{nM} \mathrm{CS}-6$ for 24, 36 and $48 \mathrm{~h}$, and cell viability was determined by MTT assay. (C) Morphological change induced by 10 and $50 \mathrm{nM}$ CS-6 in A549 cells after $48 \mathrm{~h}$ treatment (200×, magnification). Typical apoptotic morphological change in CS-6-treated cells was observed. The data are presented as mean \pm SD of three tests. $\left({ }^{*} p<0.05, * * p<0.01\right.$, significant differences between CS- 6 treatment groups and DMSO vehicle control groups). (D) Fluorescence images of A549 cells stained by AO/EB (100×, magnification), and nuclear apoptotic bodies (weight arrow) were formed in CS-6-treatet groups. (E) Cell cycle arrest of the cells induced by CS-6. Data are presented as mean \pm $\mathrm{SD}(n=3) . * p<0.01, * * p<0.01$ compared with control group. 


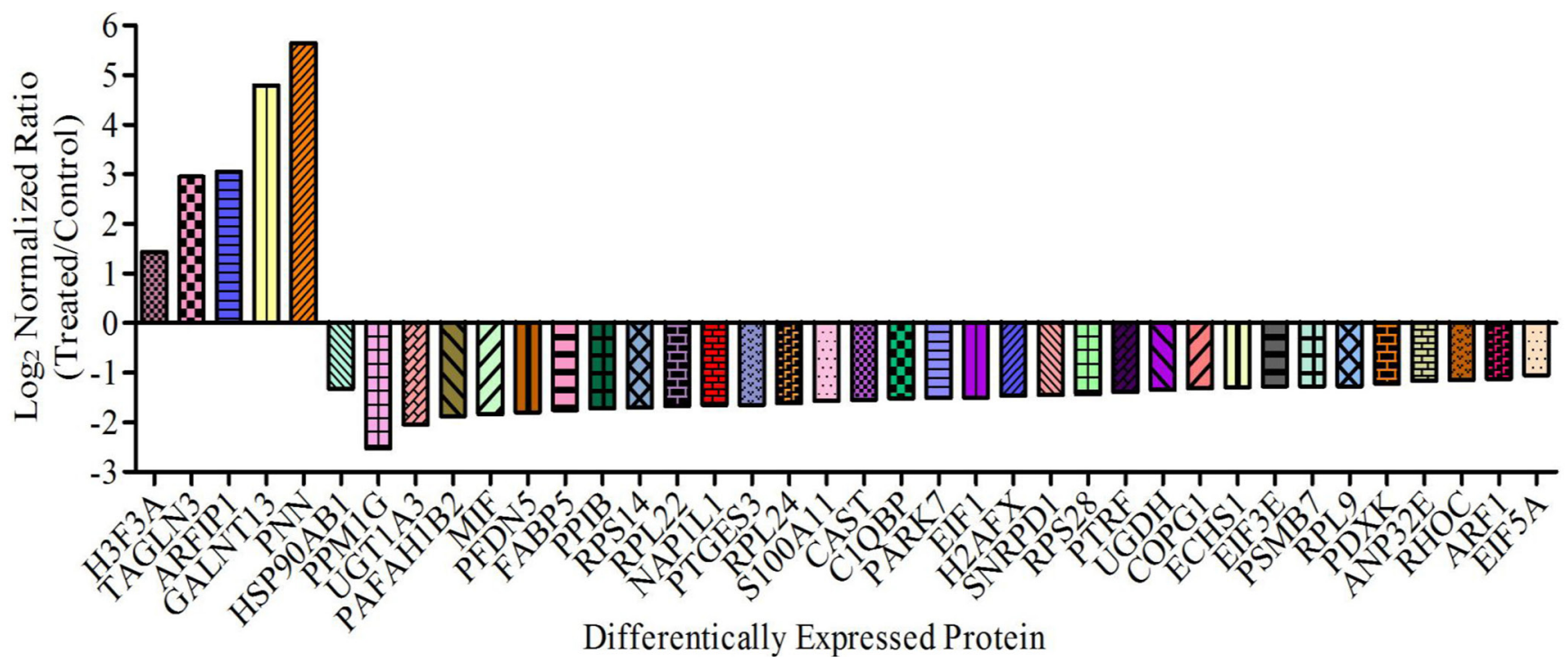

Figure 2: Proteins showing $>$ 2-fold change in abundance with CS-6 treatment $(95 \%$ confidence interval and $p$-value $<$ 0.05) are shown.

A

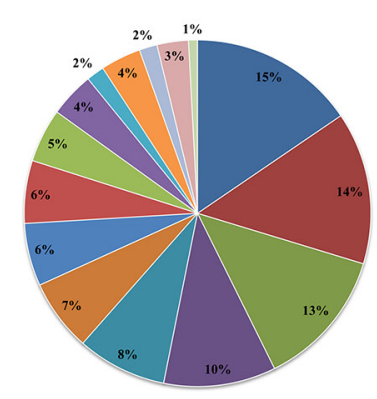

C

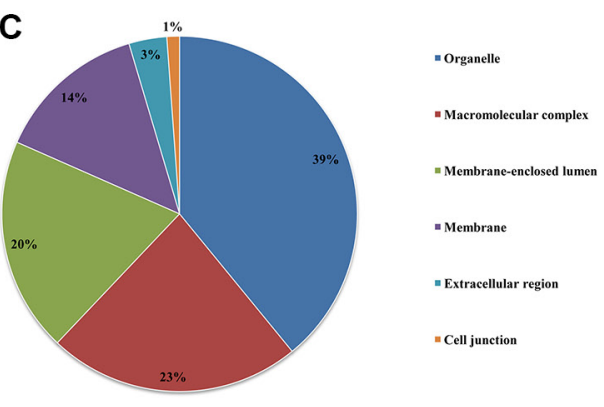

B
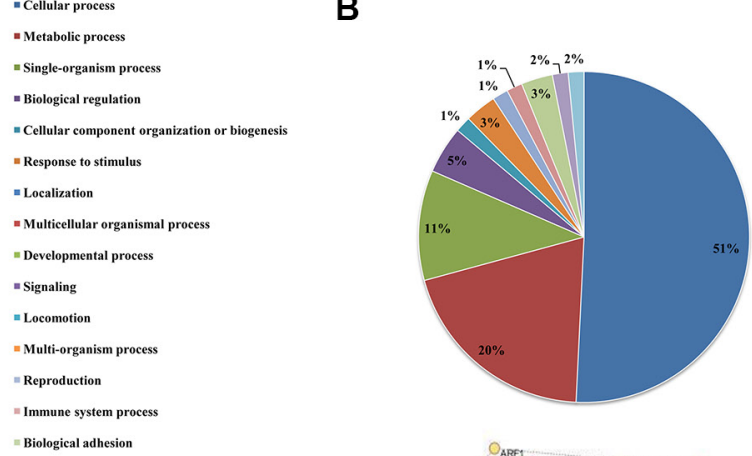

" Binding

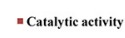

" Struetural molecule activity

- Enzyme regulator activity

- Transporter activity

- Molecular transducer activity

" Antioxidant activity

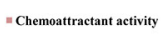

" Protein binding transcription factor activity

" Translation regulator activity

" Electron carrier activity

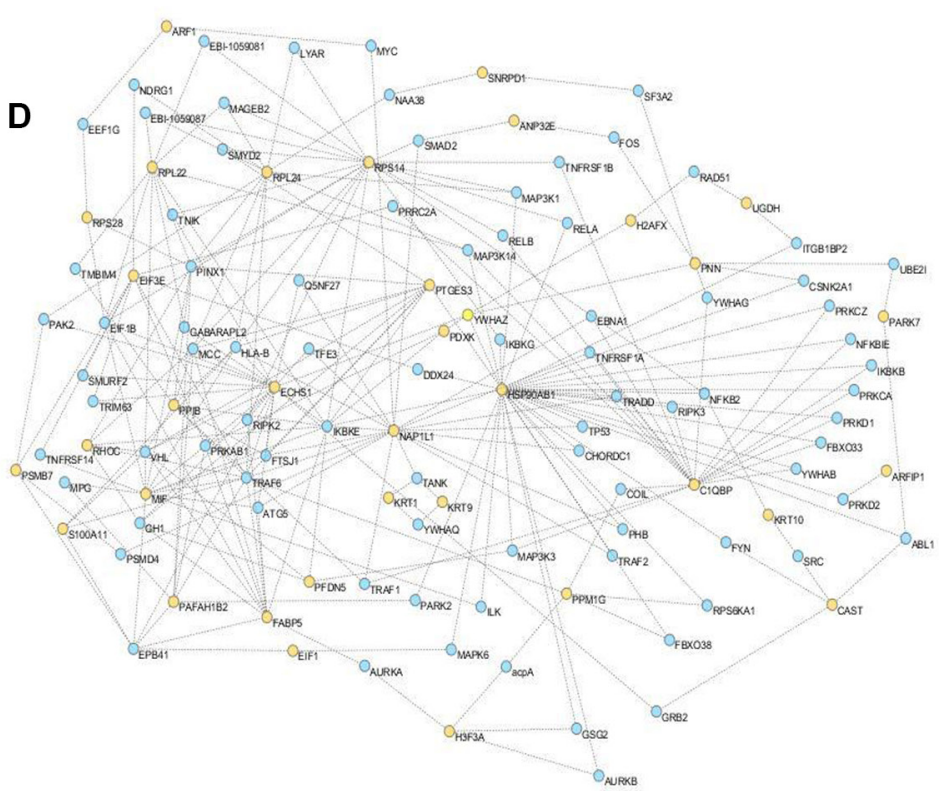

Figure 3: Gene ontology annotations of the proteome changes. Identified proteins showing $>2$ fold change were systematized on the basis of (A) biological processes, (B) molecular functions and (C) cellular component, using Blast2GO annotation. (D) Cytoscape 3.1 analysis shows the interaction network of the 31 differentially expressed proteins. 


\section{Identification of potential protein targets for CS-6}

Since treatment of cultured cells with known Hsp90 inhibitors depletes the Hsp90-dependent proteins in a concentration-dependent fashion [18, 19], our results also showed CS-6 could affect Hsp90 "client" proteins levels. Therefore, we hypothesized that CS-6 might bind to Hsp90 and subsequently inhibited its function. To test this hypothesis, computer molecular modeling assay was conducted to simulate the interactions between CS-6 and Hsp90. Molecular docking studies predicted that CS-6 would bind at the ATP binding site of Hsp90. As shown in Figure 6A, CS-6 forms five hydrogen bonds with the ATP binding pocket of the Hsp90 nucleoside domain. The $\mathrm{CO}$ motif at the lacton ring of CS-6 forms a hydrogen bond with the backbone NH of PHE138. The OH group at the $\mathrm{C} 14$ position forms strong hydrogen bonds with the backbone at ASP54 and LYS 58 simultaneously. It worth note that two hydrogen bonds were formed between the LYS 58 and the $\mathrm{O}$ of 11 hydroxyl group (Figure 6C). Moreover, the $\mathrm{OH}$ at the $\mathrm{C}-2$ accepts a hydrogen bond with the CO residue of ASP102. The result of MOLCAD surface modeling shows that the lacton ring of CS-6 extends into the deep hydrophobic cavity of the ATPbinding pocket of Hsp90, forming the hydrophobic interaction with PHE138. Therefore, our molecular modeling predicts that CS-6 binds in the ATP-binding domain of Hsp90 with interactions (Figure 6B).

In addition, as a biochemical hallmark of Hsp90 inhibition, elevation in Hsp70 levels is indicative of
ATPase activity Hsp90 ATPase activity inhibition [20]. We also detected the expression of Hsp70 after CS-6 treatment, and found that expression of Hsp70 elevated in a dose-dependent manner (Figure 4).

\section{CS-6 suppressed the expression of $\mathrm{Hsp} 90$ in nude mice tumor tissue}

Based on the results of in vitro studies, the potential of CS-6 as a novel Hsp90 inhibitor were further explored in mice with human lung cancer xenografts. Our previous experiment found that CS- 6 could significantly decrease tumor volume and weight compared the control group without obvious toxic effects in mice [9]. Moreover, the immunohistochemical staining assay was used to determine the expression of $\mathrm{Hsp} 90$ in tumor issues. The expression levels of Hsp90 were significantly decreased with CS-6 treatment in vivo, as compared with the vehicle group (Figure 7); again the results of immunohistochemistry confirmed the reliability of the proteomic analysis. These results suggested that CS-6 could inhibit Hsp90 expression in vivo, and then inhibit xenografted human lung cancer cell's growth.

\section{DISCUSSION}

Despite the latest technological and clinical advances, the survival rate of lung cancer has remained unchanged. Newer mechanistically driven approaches for treatment of lung cancer are in great demand. A number of scientific studies have suggested that, gamabufotalin
A

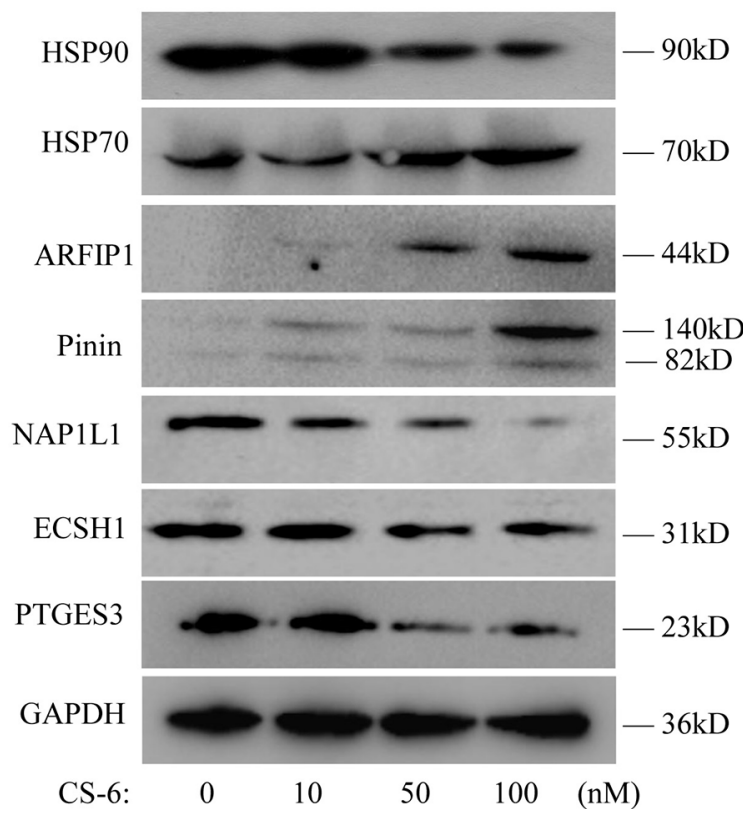

B

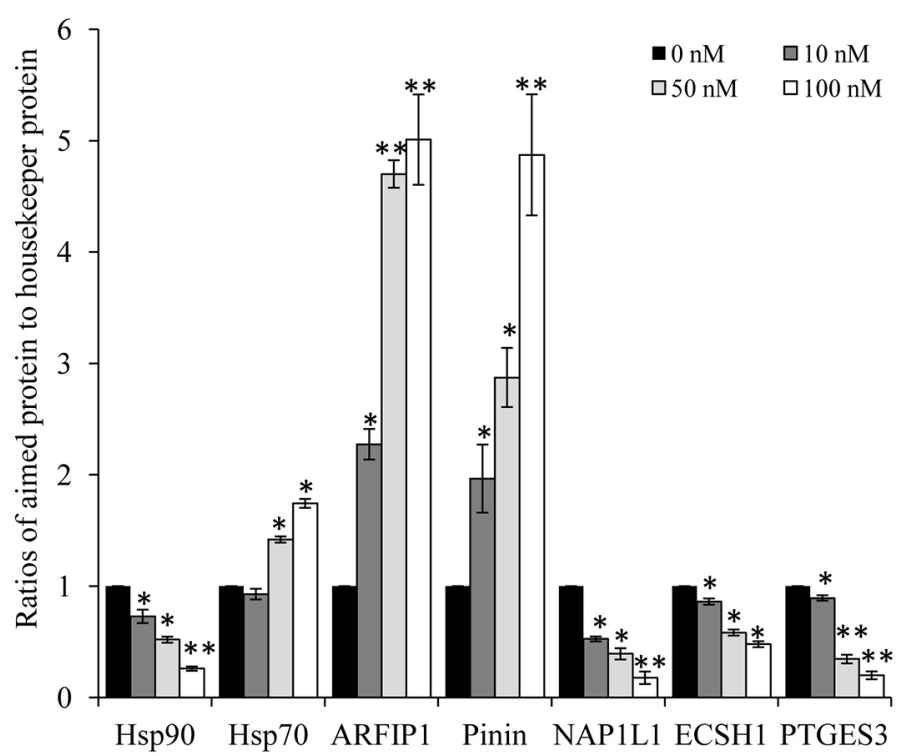

Figure 4: (A) Western blotting of Hsp90, Hsp70, ARFIP1, PNN, NAP1L1, ECSH1 and PTGES3, after treatment for $36 \mathrm{~h}$. Each blot is the representative result of three independent experiments. (B) Quantitative data of (A). ${ }^{*} p<0.01,{ }^{* *} p<0.01$ compared with control group. 
A

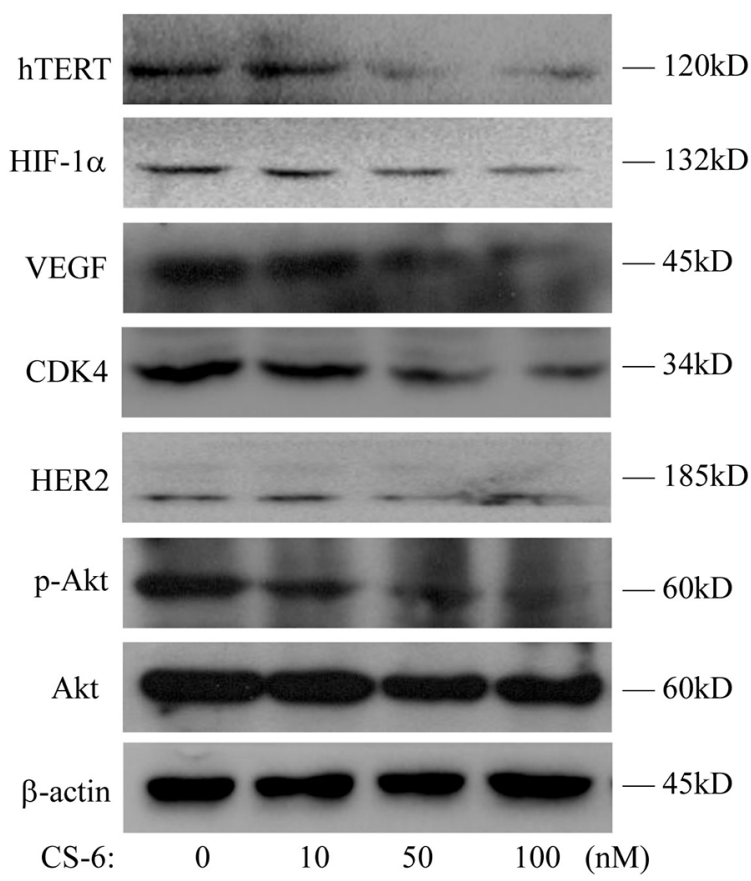

B

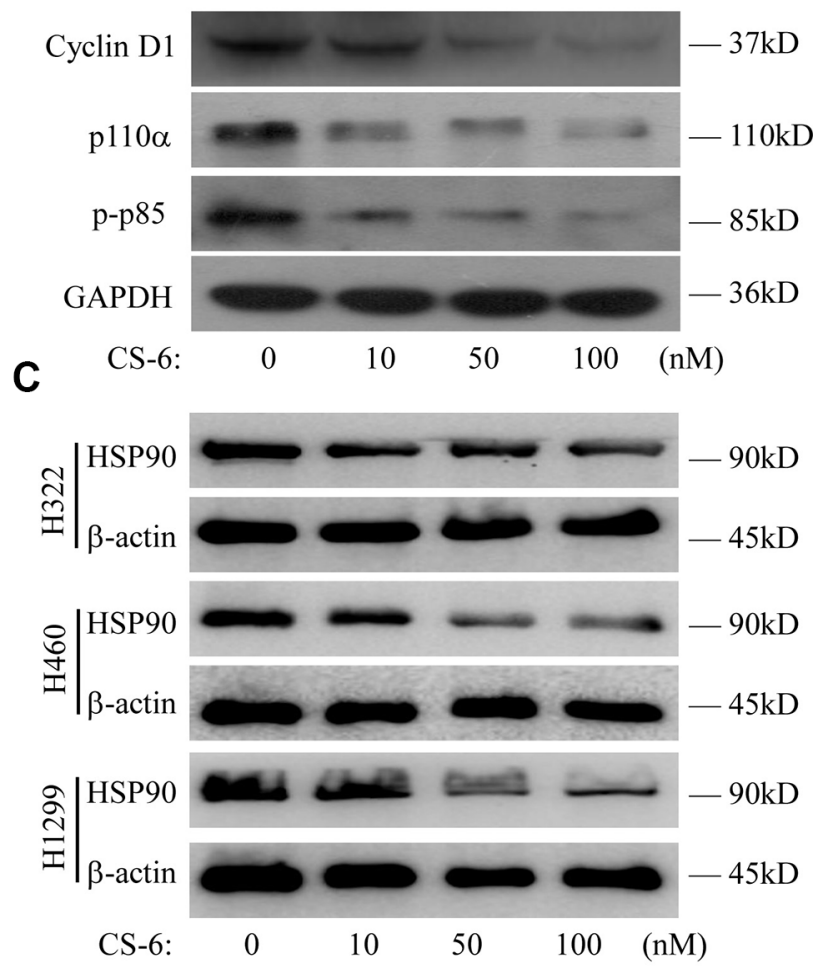

D
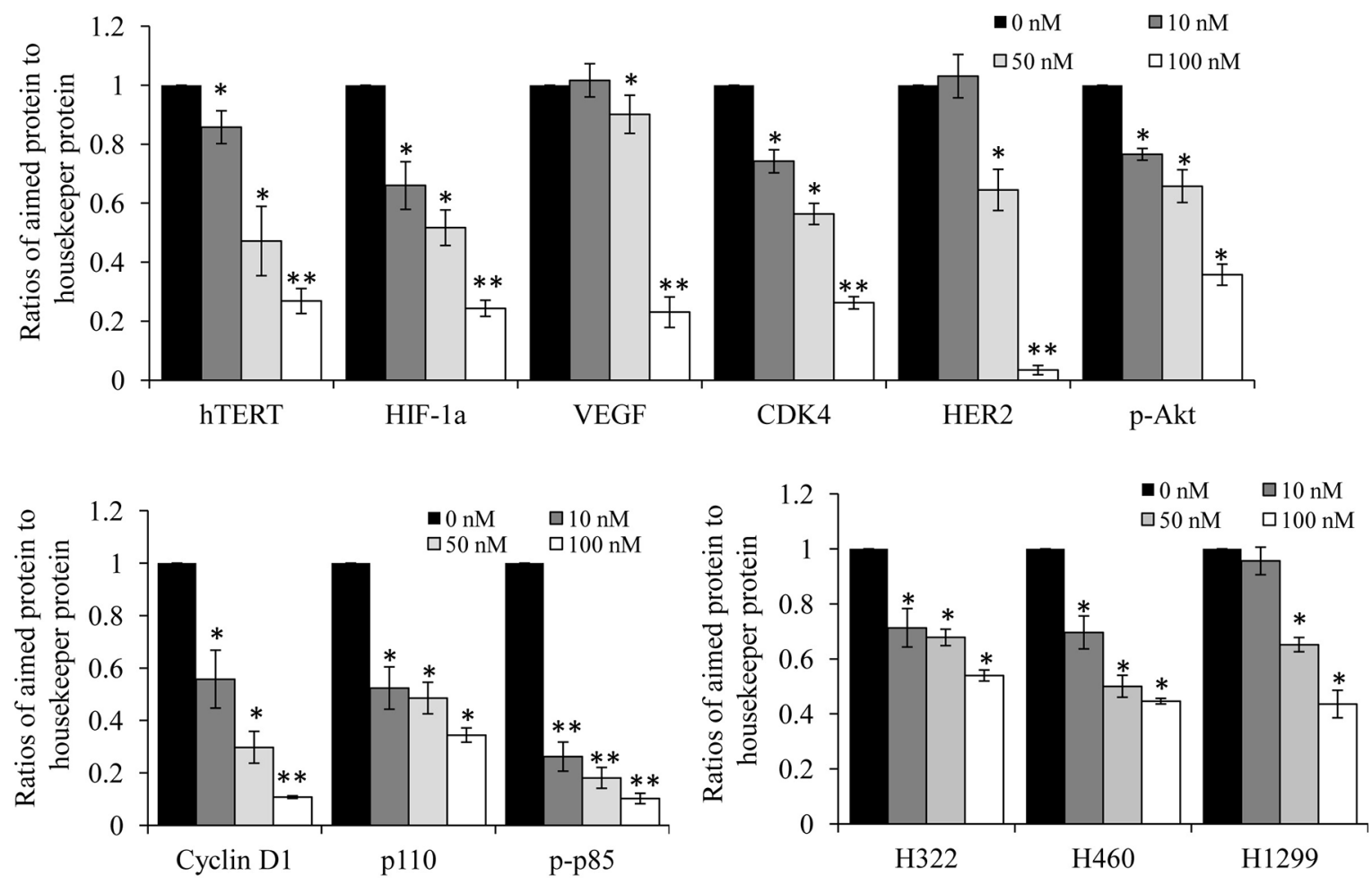

Figure 5: Western-blotting analysis of Hsp90 client proteins in CS-6-treated A549 cells. (A) Expression of senescence and cell cycle associated Hsp90 client proteins. (B) Expression of associated Hsp90 client proteins. Each blot is the representative result of three independent experiments. (C) At 36 h after treatment, the Hsp90 protein levels were analyzed by Western blotting in H1299, H322 and $\mathrm{H} 460$ cells. $\beta$-actin was used as controls for sample loading. (D) Quantitative data of (A, B and C). ${ }^{*} p<0.01,{ }^{* *} p<0.01$ compared with control group. 
(CS-6), the major derivative of bufadienolides, has great promise in the therapy of lung cancer.

In our present study, CS-6 was found to effectively inhibit NSCLC cells growth and enhance apoptosis induction dose-dependently with IC50 of only $50 \mathrm{nM}$. In addition, the results of the flow cytometry assay indicated that CS-6 might induce cell cycle arrest at G2/M phase and trigger apoptosis in A549 cells. Furthermore, a comprehensive proteomics was employed to characterize the proteome of resting and CS-6 treated human nonsmall-cell lung cancer (NSCLC) A549 cells, which might provide potential anti-cancer mechanism or the therapeutic targets of CS-6 in lung cancer. The proteomics analysis result revealed the differential regulation of the 38 proteins involved in binding, catalytic activity, structural molecule activity and enzyme regulator activity. It is noteworthy that the new and most interesting finding in our proteomic and bioinformational analysis result is the possible involvement of Hsp90 function in the effect of CS-6. Besides, the results of network construction also suggested the central role of Hsp90 in all proteins identified in the proteomics study.

Hsp90 is responsible for managing protein folding and quality control in the crowded environment of the eukaryotic cells, which facilitates the maturation and stabilization of over 200 oncogenic client proteins crucial for oncogenesis $[21,22]$. Hsp90 client protein Akt, which promotes transcription of pro-survival genes, triggers
A

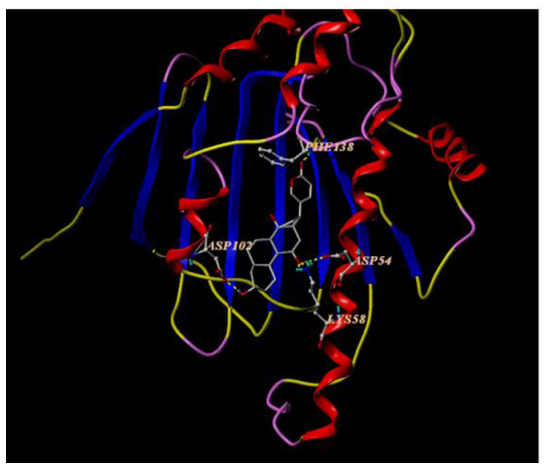

B

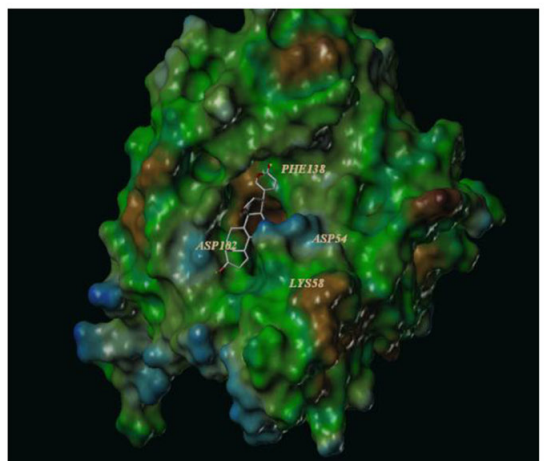

C

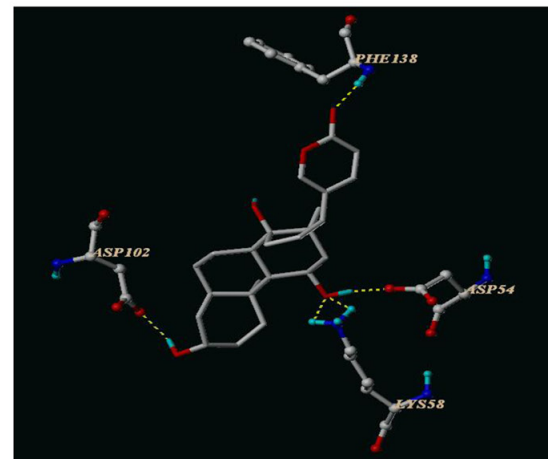

Figure 6: The best ranked pose of CS-6 in the ATP binding site of Hsp90 generated with docking. (A) Interactions of CS-6 and Hsp90 are delineated by ribbon structure, Hydrogen bonds are displayed as yellow dashed lines, and the participating amino acid residues are marked. (B) MOLCAD representation the molecular lipophilic potential surface upon the bioactive pose of CS-6 in the ATP binding site of Hsp90. The blue denotes the hydrophilic, brown for the lipophilic and green corresponds to the neutral moiety. (C) The interaction between the residues of Hsp90 and CS-6 were displayed directly without the whole protein in cartoon.

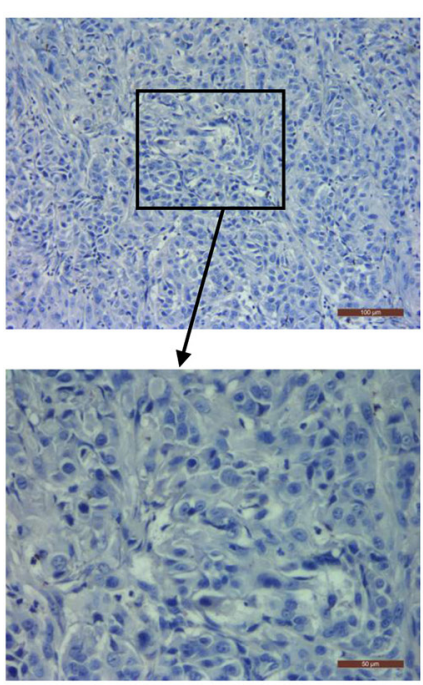

Negative control

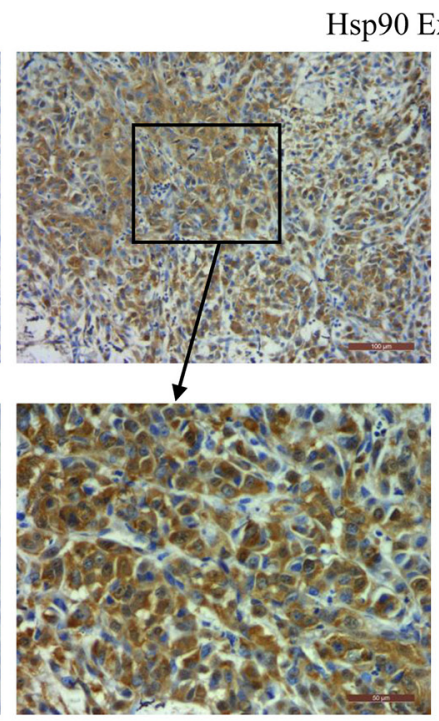

$0 \mathrm{mg} / \mathrm{kg} \mathrm{CS}-6$

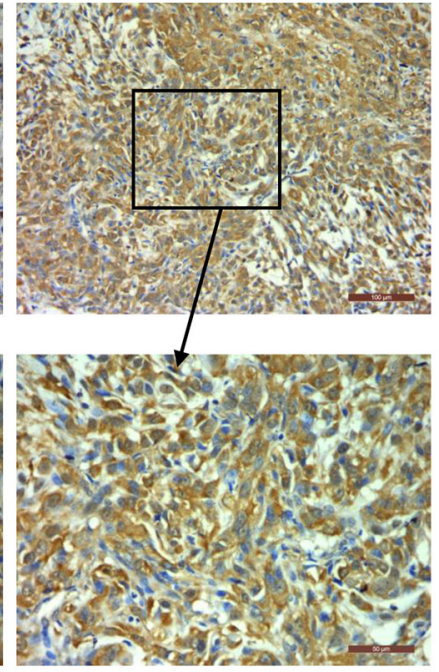

$10 \mathrm{mg} / \mathrm{kg}$ CS-6

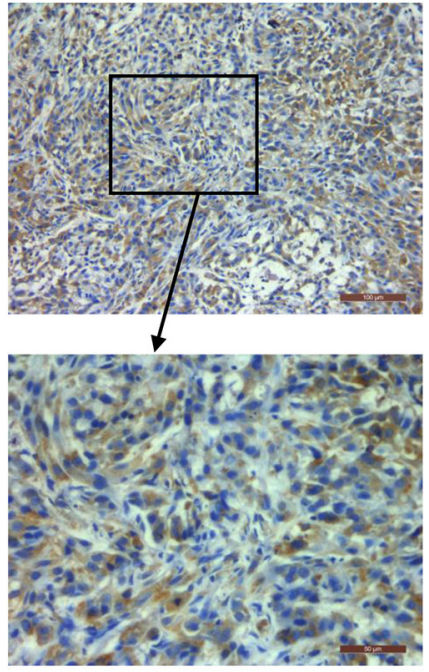

$20 \mathrm{mg} / \mathrm{kg} \mathrm{CS}-6$

Figure 7: Immunohistochemical analysis of Hsp90 expression in tumor samples. Neutral formalin fixed tumor samples were prepared from animals and analyzed by immunohistochemical staining with rabbit anti-rabbit second antibody using the Vectastain Elite $\mathrm{ABC}$ kit, and examined under a microscope. 
$\mathrm{NF}-\kappa \mathrm{B}$ activation by regulating $\kappa \mathrm{B}$ kinase (IKK) $[23,24]$. Our early study had shown that CS-6 also decreased the expression levels of $\mathrm{p}-\mathrm{I} \kappa \mathrm{B}-\alpha$ and $\mathrm{p}-\mathrm{IKK} \beta$, and inhibited translocation of the NF- $\kappa \mathrm{B}$ p $65 / \mathrm{p} 50$ proteins from cell cytoplasm to nucleus compared with control group [9]. These results indicated that CS- 6 might be a potential Hsp90 inhibitor.

Cellular senescence, a permanent and irreversible process, which could induce cell growth arrest without massive cell death $[25,26]$. Recently, the induction of cellular senescence, especially upon Hsp90 inhibition [27-29], has been proposed as a novel approach to enhance efficacy of cancer therapy with less severe side effects than cytotoxic therapies and high dose radiation. In the present study, CS-6 was found to down regulate several cell growth and cellular senescence associated Hsp90 client oncoproteins, including CKD4, Akt, hTERT, HIF-1 $\alpha$, VEGF, HER2 and VEGF. Also, we reported the correlation between CS-6 and the down regulation of Cyclin D1, p110 $\alpha$ and p-p85. These findings suggested that CS-6 inhibit cell growth and induce cellular senescence in A549 cells by down regulating cell growth and cellular senescence associated Hsp90 client proteins.

Our previous work demonstrated that CS-6 targeted $\mathrm{IKK} \beta / \mathrm{NF}-\kappa \mathrm{B}$, one member of Hsp90 client protein, to prohibit lung cancer growth. In the present study, we proposed that the anti-cancer activity of CS-6 is mediated, at least in part, by its ability to inhibit Hsp90. From above all, we believed that CS-6 showed double suppression of NF-kB activation signal pathway though inhibiting of Hsp90 and IKK $\beta$ activation.

Moreover, computational molecular docking implied that CS-6 occupied the deep hydrophobic pocket of Hsp90 with the ATP-binding sites (ASP54, LYS 58, ASP102, and PHE138), which suggested that CS-6 might block the nucleotide recognition domain binding with ATP, as a reversible inhibitor.

Based on these results, we predicted that CS-6 might have effect on Hsp90 function. To certify the prediction, the effect of CS-6 on cellular Hsp90 activity was checked by immunohistochemical staining assay. The expression levels of Hsp90 were found to be significantly decreased after CS-6 treatment in vivo, suggesting that CS-6 could inhibit cellular Hsp90 activity.

All these results suggest that targeting on multiple oncogenic pathways by CS-6, through inhibition of Hsp90, may provide an exciting novel approach in the treatment of NSCLC.

\section{MATERIALS AND METHODS}

\section{Chemicals and reagents}

Gamabufotalin (CS-6) was isolated from ChanSu by Dr. Xiaochi Ma (Dalian Medical University, Liaoning,
China) [9], which was secreted from the postauricular and skin glands of Bufo bufo gargarizans Cantor. The crude materials of ChanSu were purchased from Qingdao (Shandong Province, China). In the experiments, the CS-6 was stocked in dimethyl sulphoxide (DMSO) and kept at $-20^{\circ} \mathrm{C}$. CS- 6 was diluted into desired concentration, which was stable in the dilution with DMSO less than $0.1 \%$. RPMI 1640 and fetal bovine serum (FBS) were obtained from HyClone Laboratories (HyClone Laboratories Inc.). Dimethyl-labeled agents, $\mathrm{CH}_{2} \mathrm{O}, \mathrm{CD}_{2} \mathrm{O}$, $\mathrm{NaCNBH}_{3}$ were obtained from Sigma-Aldrich Company (St. Louis, MO).

All other agents were purchased from Sigma Chemical Co. (St. Louis, MO) unless otherwise specified. The water used in the experiments was thrice-distilled; all other materials were of analytical reagent grade.

\section{Antibodies}

The primary antibodies for Hsp90 (11405-1-AP), Hsp70 (25405-1-AP), ARFIP1 (17726-1-AP), PNN (18266-1-AP), NAP1L1 (14898-1-AP), ECSH1 (113051-AP), PTGES3 (15216-1-AP), VEGF (19003-1-AP), GAPDH (60004-1-Ig), $\beta$-actin (20536-1-AP) and all the secondary antibodies were obtained from Proteintech Group (Proteintech Group, Inc., USA). The primary antibodies for HIF-1 $\alpha$ (sc-10790) and hTERT (sc-7212) were obtained from Santa Cruz Biotechnology (Santa Cruz, CA, USA). The primary antibodies for Akt (4691), p-Akt (4060), p110 $\alpha$ (4249), and p-p85 (4228) were obtained from Cell Signaling Technology (Cell Signaling Technology Inc., USA).

\section{Cell culture}

Human NSCLC A549 cell line was from ATCC (Manassas, VA). Cells were maintained in RPMI 1640 medium supplemented with $10 \%$ FBS, 100 units $/ \mathrm{ml}$ penicillin and $100 \mu \mathrm{g} / \mathrm{ml}$ streptomycin. The cells were maintained at $37^{\circ} \mathrm{C}$ with $5 \% \mathrm{CO}_{2}$ in a humidified atmosphere.

\section{Cell viability assay and morphological changes}

Cell viability was determined by 5-diphenyltetrazolium bromide (MTT) assay (Sigma). Briefly, A549 cells ( $4 \times 10^{3}$ cells) were seeded in 96-well plates in normal growth medium and allowed to adhere for overnight. Then the medium was replaced with normal medium containing various amounts of CS-6 $(0,5,10,50$, 100 and $500 \mathrm{nM}$ ) for 24,36 and $48 \mathrm{~h}$. After that, $15 \mu \mathrm{L}$ MTT solution was added, and the growths of cells were measured after $4 \mathrm{~h}$ of incubation. To examine the effect of CS-6 on cell morphology, the cell images were captured with a Leica DM 14000B microscope after treated with appropriate CS-6. All experiments were performed in triplicate. 


\section{Cell cycle analysis}

Cell cycle analysis was conducted by FACS Accuri C6 (Genetimes Technology Inc.) to evaluate the effects of CS-6 on cell cycle arrest. Briefly adherent and detached cells were harvested with trypsin, washed with PBS three times, and then fixed in ice-cold $70 \%$ ethanol at $4{ }^{\circ} \mathrm{C}$ for 4 h. After centrifugation at $1000 \mathrm{rpm}$ for $5 \mathrm{~min}$, cells were resuspended in propidium iodide stain buffer $(0.2 \%$ Triton $\mathrm{X}-100,100 \mu \mathrm{g} / \mathrm{mL}$ DNase-free RNase A, and $50 \mu \mathrm{g} / \mathrm{mL}$ propidium iodide in $\mathrm{PBS}$ ) for $30 \mathrm{~min}$ in the dark. Flow cytometric analysis was conducted using FACS Accuri C6 (Genetimes Technology Inc.).

\section{AO/EB staining}

Acridine orange/ethidium bromide (AO/EB) staining is used to visualize nuclear changes and apoptotic body formation. The A549 cells $\left(2 \times 10^{5}\right.$ cells $\left./ \mathrm{mL}\right)$ were seeded in 6-well plates for $24 \mathrm{~h}$ and treated with various concentrations of CS-6 $(0,10$ and $50 \mu \mathrm{M})$ for $36 \mathrm{~h}$. After incubation, the cells were washed with PBS. Then, the mixture solution containing same volume of $\mathrm{AO}$ and $\mathrm{EB}$ (diluted in PBS for $100 \mu \mathrm{g} / \mathrm{ml}$ ) was put onto the cells. The images of the cells were observed using a Leica DM 14000B fluorescence microscope fitted with digital camera.

\section{Protein preparation and tryptic digestion}

A549 cells were exposed to $50 \mathrm{nM} \mathrm{CS}-6$ for $36 \mathrm{~h}$, and then harvested for protein extraction on ice. The cell pellets were dissolved in a cell lysis buffer ( $8 \mathrm{M}$ urea) plus $1 \%(\mathrm{v} / \mathrm{v})$ protease inhibitor cocktail set. The suspension was homogenized on ice for $1 \mathrm{~min}$, ultrasonicated for $30 \mathrm{~s}$ and centrifuged at $25000 \mathrm{~g}$ for $30 \mathrm{~min}$ at $4^{\circ} \mathrm{C}$, and the supernatants were harvested and frozen at $-80^{\circ} \mathrm{C}$. Protein concentrations were determined using a BCA protein assay kit according to the manufacturer's instructions. Proteins were reduced with $10 \mathrm{mM}$ dithiothreitol for $30 \mathrm{~min}$ at $56^{\circ} \mathrm{C}$, then alkylated with $20 \mathrm{mM}$ iodoacetamide for $1 \mathrm{~h}$ at room temperature in the dark. Cell lysates were diluted and digested with a trypsin to protein ratio of 1:25 (W/W) at $37^{\circ} \mathrm{C}$ overnight. The resulting peptide solutions were acidified with $1 \% \mathrm{FA}$, and desalted on a C18 trap column. Eluted peptides were lyophilized to complete dryness, and stored at $-80^{\circ} \mathrm{C}$ until needed.

\section{Stable isotope dimethyl labeling}

Stable isotope dimethyl labeling was performed according to the reported protocol [12] with the appropriate improvements. Briefly, the samples were labeled by light $\left(0.2 \% \mathrm{CH}_{2} \mathrm{O}\right.$ and $\left.30 \mathrm{mM} \mathrm{NaBH}_{3} \mathrm{CN}\right)$ and heavy $(0.2 \%$ $\mathrm{CD}_{2} \mathrm{O}$ and $30 \mathrm{mM} \mathrm{NaBH}{ }_{3} \mathrm{CN}$ ) dimethylation reagents, respectively. After keeping the reaction solution in $25^{\circ} \mathrm{C}$ for $1 \mathrm{~h}, 2 \mathrm{~mL}$ of $10 \%$ (vol/vol) ammonia and $5 \mathrm{~mL}$ of $10 \%$
( vol/vol) formic acid in water were successively added to quench the reaction. The isotopically labeled peptides were mixed together, desalted by a C18 solid-phase extraction column, lyophilized to powder and re-dissolved in $0.1 \%$ FA in $\mathrm{H}_{2} \mathrm{O}$ for the following LC-MS/MS analysis.

\section{NanoLC-MS/MS analysis}

The peptide samples were analyzed by nano-RPLCESI-MS/MS with an LTQ-OrbitrapElite mass spectrometer (Thermo Fisher Scientific, San Jose, CA, USA) equipped with a Dionex ultimate 3000 liquid chromatography and an ESI probe Ion Max Source with a nanospray kit. The spectrometer was controlled by Xcalibur software version 2.2 (Thermo Fisher, Waltham, MA, USA). The peptides were separated on a C18 capillary column (30 $\mathrm{cm}, 75 \mu \mathrm{m}$ i.d. $/ 375 \mu \mathrm{m}$ o.d.) packed with $\mathrm{C} 18$ silica particles $(5 \mu \mathrm{m}, 100 \AA)$ with a 145 min gradient from 10 to $40 \%$ buffer B ( $98 \%$ ACN $/ 0.1 \%$ FA) and analyzed on the mass spectrometer. Mass spectra were acquired in a data-dependent mode. MS1 spectra were measured at a resolution of $6 \times 10^{4}$ and the top 10 most abundant ions with an isolation window of $2 \mathrm{~m} / \mathrm{z}$ were selected for sequencing and fragmented in the data-dependent CID mode with a normalized collision energy of 35\%, activation Q of 0.25 , activation time of $10 \mathrm{~ms}$, and one microscan. The sample was analyzed in triplicate.

\section{Data processing}

Data analysis was accomplished by using MaxQuant software (http://maxquant.org/, version 1.3.0.3) against IPI human database (v3.80). Peptides were searched using the following parameters: fully tryptic cleavage constraints; up to two internal cleavage sites allowed for tryptic digestion; carbamidomethylation as a fixed modification; oxidation of methionine and protein $\mathrm{N}$-terminal acetylation as variable modifications; dimethyl $(+28.0313 \mathrm{Da})$ and dimethyl $(+32.0564) \mathrm{N}$-termini and $\mathrm{K}$ set as light/heavy labels for quantification. The peptide mass tolerance was set at $20 \mathrm{ppm}$ and MS/MS tolerance was set at $0.5 \mathrm{Da}$. Protein and peptides FDRs were $1 \%$. The rest of the parameters follow the default settings of MaxQuant software.

\section{Bioinformatics analysis}

Gene Ontology annotations including cellular component, biological process, and molecular function were performed with Blast2GO program (Version 2.7.0) [30-32]. A global protein-protein interaction network was generated using Cytoscape (Version 3.1) [33, 34] .

\section{Western blot analysis}

A549 cells were treated with various concentrations of CS-6. Total cell proteins were prepared using mammalin 
protein extraction reagent (purchased from Beijing CoWin Bioscience Co., Ltd.). The concentration of proteins was determined using a BCA protein assay kit. Cell lysate proteins $(40 \mu \mathrm{g})$ were separated by electrophoresis on a 7.5 $12 \%$ sodium dodecyl sulfate-polyacrylamide minigels (SDSPAGE) gels and then electrophoretically transferred to PVDF membranes. After that, the membranes were incubated with $5 \%$ dehydrated skim milk for $2 \mathrm{~h}$ at room temperature. Western blots were probed with the specific antibodies. Proteins were detected by enhanced chemiluminescence system according to the manufacturer's instructions. Similar experiments were performed at least three times.

\section{Molecular modeling}

The molecular docking studies were performed to explore the potential binding mode between CS-6 and Hsp90 protein complex. CS-6 was optimized using the semiempirical PM3 method with the Polak-Ribie're conjugate gradient algorithm with an RMS gradient of $0.01 \mathrm{kcal} \mathrm{mol}^{-1}$ $\AA^{-1}$ as convergence criterion. The optimized structure of CS- 6 was docked into the active site of Hsp90 with ligand (PDB Code: 3QDD). The crystallographic ligand was extracted from the active site, and the Surflex-Dock program was used for the docking calculations with default parameters. MOLCAD surfaces were generated for visualizing the binding mode of the docked protein-ligand complexes

\section{Animal studies}

As reported in our previous work [9], all animals were maintained, and animal experiments were done in SPF Laboratory Animal Center at Dalian medical university. A549 cells $\left(2 \times 10^{6}\right.$ in $100 \mu \mathrm{L}$ PBS $)$ were injected subcutaneously near the axillary fossa of female nu/nu mice using a 27-gauge needle. The tumor cellinoculated mice were randomly divided into three groups: group A was treated with PBS; group B with $5 \mathrm{mg} / \mathrm{kg}$ CS-6; group C with $10 \mathrm{mg} / \mathrm{kg} \mathrm{CS}-6$ by intraperitoneal injection every day. After treated with CS-6 for two weeks, all experimental mice were killed with ether anesthesia. To determine Hsp90 expression in neoplastic tissues, the tumors were harvested and freshly fixed in $10 \%$ neutral formalin and desiccated and embedded paraffin. $4 \mu \mathrm{m}$ sections were stained with specific Hsp90 antibody (1:100). The images were examined under a Leica DM 14000B fluorescence microscope equipped with a digital camera.

\section{Statistical analysis}

All experiments were repeated at least three times. Data are represented as mean \pm standard deviation (SD). Analysis of variance and Student's $t$-test were used to compare the values of the test and control samples in vitro and in vivo. $P<0.05$ was considered to be a statistically significant difference. SPSS 17.0 software was used for all statistical analysis.

\section{CONCLUSIONS}

Our study demonstrated the in vitro and in vivo antitumor effect of a novel Hsp90 inhibitor, CS-6, on the NSCLC cell line A549. To the best of our knowledge, it might be the first time to report the treatment of CS-6 on Hsp90 expression and to demonstrate the underlying mechanisms both in vitro and in vivo. CS-6 inhibited cell growth, cell migration, tumor sphere formation and induced cellular senescence in A549. By using a proteomics technique and bioinformatics analysis, 38 target-related proteins and the regulated network of CS-6 were found. The ability of CS-6 to target multiple NSCLC oncoproteins, make it a potent antitumor agent in treatment of NSCLC. Together with the tumor suppressive effect of CS-6 in nude mice tumorigenicity assay, this study provided preclinical evidence of using CS-6 as a new therapeutic agent in treatment of NSCLC. The results of the present study shed light on the anticancer mechanism of CS-6 from a molecular perspective. Besides, understanding of the cytotoxicity mechanism of CS-6 will be helpful to the study the use of likely promising bufadienolides. Furthermore we are continuing to find new bufadienolides from toad venom and other herbs. It is possible that we can obtain promising bufadienolides for cancer therapy either by isolating from herbs or by modifying natural bufadienolides.

\section{ACKNOWLEDGMENTS}

We thank the NSFC (81302809, 81274047, 81473334, 81503201 and 81303146), Dalian Outstanding Youth Science and Technology Talent (2014J11JH132 and 2015J12JH201), Distinguished Professor of Liaoning Province, Liaoning BaiQianWan Talents Program, and the Innovation Team of Dalian Medical University for their financial support.

\section{CONFLICTS OF INTEREST}

The authors have declared that there are no conflicts of interest.

\section{Authors' contribution}

Participated in the research design: M. XC., Z. LY., Y. QX., Y. ZL, and W. XB. Conducted experiments: W. Y., W.C., H. XK., D. S., T. XG., W.X, and Z. BJ. Contributed 
new reagents or analytic tools: H. XK., Z. LY., Z. LR., and M. XC. Performed data analysis: M. XC., D. S., Z. LY., Y, QX., Y. ZL., and W. Y.. Wrote or contributed to the writing of the manuscript: M. XC., Z. LY., Y. QX., Y. ZL. Z. LY. and Y. ZL contributed equally to this work.

\section{REFERENCES}

1. Siegel RL, Miller KD, Jemal A. Cancer statistics, 2016. CA Cancer J Clin. 2016; 66:7-30.

2. Chen W, Zheng R, Baade PD, Zhang S, Zeng H, Bray F, Jemal A, Yu XQ, He J. Cancer statistics in China, 2015. CA Cancer J Clin. 2016; 66:115-132.

3. Forde PM, Ettinger DS. Targeted therapy for non-small-cell lung cancer: past, present and future. Expert Rev Anticancer Ther. 2013; 13:745-758.

4. May BH, Lu C, Bennett L, Hugel HM, Xue CC. Evaluating the traditional Chinese literature for herbal formulae and individual herbs used for age-related dementia and memory impairment. Biogerontology. 2012; 13:299-312.

5. Ma XC, Zhang BJ, Xin XL, Huang SS, Deng S, Zhang HL, Shu XH, Diao YP, Cui J. Simultaneous quantification of seven major bufadienolides in three traditional Chinese medicinal preparations of chansu by HPLC-DAD. Nat Prod Commun. 2009; 4:179-184.

6. Zhang Y, Tang X, Liu X, Li F, Lin X. Simultaneous determination of three bufadienolides in rat plasma after intravenous administration of bufadienolides extract by ultra performance liquid chromatography electrospray ionization tandem mass spectrometry. Anal Chim Acta. 2008; 610:224-231.

7. $\mathrm{Hu} \mathrm{K}, \mathrm{Zhu} \mathrm{L}$, Liang H, Hu F, Feng J. Improved antitumor efficacy and reduced toxicity of liposomes containing bufadienolides. Arch Pharm Res. 2011; 34:1487-1494.

8. Cheng W, Tan YF, Tian HY, Gong XW, Chen KL, Jiang RW. Two new bufadienolides from the rhizomes of Helleborus thibetanus with inhibitory activities against prostate cancer cells. Nat Prod Res. 2014; 28:901-908.

9. Yu Z, Guo W, Ma X, Zhang B, Dong P, Huang L, Wang X, Wang C, Huo X, Yu W, Yi C, Xiao Y, Yang W, et al. Gamabufotalin, a bufadienolide compound from toad venom, suppresses COX-2 expression through targeting IKKbeta/NF-kappaB signaling pathway in lung cancer cells. Mol Cancer. 2014; 13:203.

10. Moreno YBL, Katz A, Miklos W, Cimmino A, Tal DM, Ainbinder E, Zehl M, Urban E, Evidente A, Kopp B, Berger W, Feron O, Karlish S, et al. Hellebrin and its aglycone form hellebrigenin display similar in vitro growth inhibitory effects in cancer cells and binding profiles to the alpha subunits of the $\mathrm{Na}+\mathrm{K}+$-ATPase. Mol Cancer. 2013; 12:33.

11. Yu Z, Li T, Wang C, Deng S, Zhang B, Huo X, Zhang B, Wang X, Zhong Y, Ma X. Gamabufotalin triggers c-Myc degradation via induction of WWP2 in multiple myeloma cells. Oncotarget. 2016; 7:15725-37. doi: 10.18632/ oncotarget.7398.

12. Boersema PJ, Raijmakers R, Lemeer S, Mohammed S, Heck AJ. Multiplex peptide stable isotope dimethyl labeling for quantitative proteomics. Nat Protoc. 2009; 4:484-494.

13. Lau HT, Suh HW, Golkowski M, Ong SE. Comparing SILAC- and stable isotope dimethyl-labeling approaches for quantitative proteomics. J Proteome Res. 2014; 13:4164-4174.

14. Hsu JL, Huang SY, Chow NH, Chen SH. Stable-isotope dimethyl labeling for quantitative proteomics. Anal Chem. 2003; 75:6843-6852.

15. Geng J, Xiao S, Zheng Z, Song S, Zhang L. Gambogic acid protects from endotoxin shock by suppressing proinflammatory factors in vivo and in vitro. Inflamm Res. 2013; 62:165-172.

16. Huang W, Wu QD, Zhang M, Kong YL, Cao PR, Zheng W, Xu JH, Ye M. Novel Hsp90 inhibitor FW-04-806 displays potent antitumor effects in HER2-positive breast cancer cells as a single agent or in combination with lapatinib. Cancer Lett. 2015; 356:862-871.

17. Liang W, Miao S, Zhang B, He S, Shou C, Manivel P, Krishna R, Chen Y, Shi YE. Synuclein gamma protects Akt and mTOR and renders tumor resistance to Hsp90 disruption. Oncogene. 2015; 34:2398-2405.

18. Zhao R, Houry WA. Molecular interaction network of the Hsp90 chaperone system. Adv Exp Med Biol. 2007; 594:27-36.

19. Davenport J, Manjarrez JR, Peterson L, Krumm B, Blagg BS, Matts RL. Gambogic acid, a natural product inhibitor of Hsp90. J Nat Prod. 2011; 74:1085-1092.

20. Peng B, Xu L, Cao F, Wei T, Yang C, Uzan G, Zhang D. Hsp90 inhibitor, celastrol, arrests human monocytic leukemia cell U937 at G0/G1 in thiol-containing agents reversible way. Mol Cancer. 2010; 9:79.

21. Whitesell L, Santagata S, Lin NU. Inhibiting Hsp90 to treat cancer: a strategy in evolution. Curr Mol Med. 2012; 12:1108-1124.

22. Trepel J, Mollapour M, Giaccone G, Neckers L. Targeting the dynamic Hsp90 complex in cancer. Nat Rev Cancer. 2010; 10:537-549.

23. Shimp SK, 3rd, Parson CD, Regna NL, Thomas AN, Chafin CB, Reilly CM, Nichole Rylander M. Hsp90 inhibition by 17-DMAG reduces inflammation in J774 macrophages through suppression of Akt and nuclear factorkappaB pathways. Inflamm Res. 2012; 61:521-533.

24. Gopalakrishnan R, Matta H, Chaudhary PM. A purine scaffold Hsp90 inhibitor BIIB021 has selective activity against KSHV-associated primary effusion lymphoma and blocks vFLIP K13-induced NF-kappaB. Clin Cancer Res. 2013; 19:5016-5026.

25. Campisi J, di Fagagna FD. Cellular senescence: when bad things happen to good cells. Nat Rev Mol Cell Biol. 2007; 8:729-740. 
26. Collado M, Serrano M. Senescence in tumours: evidence from mice and humans. Nat Rev Cancer. 2010; 10:51-57.

27. Restall IJ, Lorimer IA. Induction of premature senescence by hsp90 inhibition in small cell lung cancer. PLoS One. 2010; 5:e11076.

28. Ernst A, Anders H, Kapfhammer H, Orth M, Hennel R, Seidl K, Winssinger N, Belka C, Unkel S, Lauber K. Hsp90 inhibition as a means of radiosensitizing resistant, aggressive soft tissue sarcomas. Cancer Lett. 2015; 365:211-222.

29. Chan KC, Ting CM, Chan PS, Lo MC, Lo KW, Curry JE, Smyth T, Lee AW, Ng WT, Tsao GS, Wong RN, Lung ML, Mak NK. A novel Hsp90 inhibitor AT13387 induces senescence in EBV-positive nasopharyngeal carcinoma cells and suppresses tumor formation. Mol Cancer. 2013; 12:128.

30. Gotz S, Garcia-Gomez JM, Terol J, Williams TD, Nagaraj SH, Nueda MJ, Robles M, Talon M, Dopazo J, Conesa A. High-throughput functional annotation and data mining with the Blast2GO suite. Nucleic Acids Res. 2008; 36:3420-3435.

31. Conesa A, Gotz S, Garcia-Gomez JM, Terol J, Talon M, Robles M. Blast2GO: a universal tool for annotation, visualization and analysis in functional genomics research. Bioinformatics. 2005; 21:3674-3676.

32. Ahmad Y, Sharma NK, Ahmad MF, Sharma M, Garg I, Srivastava M, Bhargava K. The proteome of Hypobaric Induced Hypoxic Lung: Insights from Temporal Proteomic Profiling for Biomarker Discovery. Scientific Reports. 2015; 5.

33. Shannon P, Markiel A, Ozier O, Baliga NS, Wang JT, Ramage D, Amin N, Schwikowski B, Ideker T. Cytoscape: a software environment for integrated models of biomolecular interaction networks. Genome Res. 2003; 13:2498-2504.

34. Kohl M, Wiese S, Warscheid B. Cytoscape: software for visualization and analysis of biological networks. Methods Mol Biol. 2011; 696:291-303. 